\title{
Insurance Coverage
}

and Preventive Care

Among Adults

Lisa M. Lines, Matthew Urato, Michael T. Halpern, and Sujha Subramanian

April 2014 


\section{About the Authors}

Lisa M. Lines, PhD, MPH, is a health services researcher in the Division of Health Services and Social Policy Research at RTI International in

Waltham, Massachusetts.

Matthew Urato, MA, is a programmer at RTI in Research Triangle Park, North Carolina.

Michael T. Halpern, MD, PhD, MPH, is a health services researcher in RTI's Social Policy, Health, and Economics Research group and is located in Washington, DC

Sujha Subramanian, $\mathrm{PhD}$, is a senior health economist in RTI's Division of Health Services and Social Policy Research and is located in Waltham, Massachusetts.
RTI Press publication RR-0021-1404

This PDF document was made available from www.rti.org as a public service of RTI International. More information about RTI Press can be found at http://www.rti.org/rtipress.

RTI International is an independent, nonprofit research organization dedicated to improving the human condition by turning knowledge into practice. The RTI Press mission is to disseminate information about RTI research, analytic tools, and technical expertise to a national and international audience. RTI Press publications are peer-reviewed by at least two independent substantive experts and one or more Press editors.

\section{Suggested Citation}

Lines LM, Urato M, Halpern MT, Subramanian S. Insurance coverage and preventive care among adults (RTI Press publication No. RR-0021-1404). Research Triangle Park (NC): RTI Press; 2014 Apr. Available from: http://www.rti.org/rtipress.
This publication is part of the RTI Research Report series.

RTI International

3040 East Cornwallis Road PO Box 12194

Research Triangle Park, NC 27709-2194 USA

Tel: $\quad+1.919 .541 .6000$

Fax: $\quad+1.919 .541 .5985$

E-mail: rtipress@rti.org

Website: www.rti.org
(C)2014 Research Triangle Institute. RTI International is a trade name of Research Triangle Institute.

All rights reserved. This report is protected by copyright. Credit must be provided to the author and source of the document when the content is quoted. Neither the document nor partial or entire reproductions may be sold without prior written permission from the publisher.

www.rti.org/rtipress 


\title{
Insurance Coverage and Preventive Care Among Adults
}

\author{
Lisa M. Lines, Matthew Urato, Michael T. Halpern, \\ and Sujha Subramanian
}

$\begin{array}{lr}\text { Contents } & \\ \text { Introduction } & 2 \\ \text { Methods } & 2 \\ \quad \begin{array}{l}\text { Data Source and Study } \\ \quad \text { Population }\end{array} \\ \quad \text { Outcome Variables and } \\ \quad \text { Measures }\end{array}$

\section{Abstract}

The Affordable Care Act (ACA) is intended to provide health insurance to all US citizens, but many people will likely continue to have gaps in their insurance coverage after reform. For this study, we used longitudinal survey data from Panel 11 (2006-2007) of the Medical Expenditure Panel Survey to examine the effect of gaps in insurance coverage on adults' receipt of preventive screening. We categorized individuals $(n=8,985)$ between the ages of 18 and 64 at baseline as continuously insured (private only or any public), intermittently insured, or continuously uninsured. Outcome measures were routine checkup, blood pressure check, cholesterol check, flu shot, sigmoidoscopy or colonoscopy, mammogram, Pap smear, and an overall composite measure. Logistic regression models controlled for age, sex, race, limited English proficiency, education, urbanicity, census region, income, perceived health, and employment status. Crude rates of receiving preventive services were generally highest for those with public insurance and lowest for the continuously uninsured. In adjusted analyses, having intermittent coverage increased the odds of receiving no preventive services to 1.64 compared with continuous private insurance. Continuously lacking insurance increased the odds of receiving no preventive services to 4.41 compared with continuous private coverage. The effect of intermittent coverage was larger than the effect of race/ethnicity, education, where individuals lived, perceived health status, or employment status. Lack of continuous health insurance is a critical barrier to receiving appropriate health care services. Implementation of the ACA will be less successful if gaps in coverage are not prevented. 


\section{Introduction}

The employer-based health insurance system in the United States creates an environment of potentially unstable health insurance coverage in which gaps in coverage may occur. According to a 2011 survey of US adults, more than 26 percent were either uninsured or had been without health insurance in the previous 12 months. ${ }^{1}$ Although the Affordable Care Act (ACA) was intended to provide affordable health insurance to all US citizens, gaps in coverage are likely to persist. For example, short gaps in coverage (up to 3 months) will be allowed without a tax penalty under the new regulations. ${ }^{2}$ Even if the United States achieves broad compliance with health insurance requirements, many people will still experience gaps in their coverage because of paperwork requirements, changing eligibility, inability to pay, and simple lack of knowledge.

As of February 2014, only 25 states and the District of Columbia have chosen to expand Medicaid access under the ACA. ${ }^{3}$ The lack of expanded access in other states perpetuates the existing barriers to obtaining affordable health insurance for many individuals. Insurance available on the exchanges will likely cost more than the tax penalty for not being insured, potentially leading to continued noncoverage and intermittent coverage.

Interruptions in insurance coverage can result in barriers to preventive care and chronic disease management, resulting in expensive hospitalizations or emergency department visits and lower quality of care. ${ }^{4,5}$ In a 2005 survey, 59 percent of uninsured adults who had a chronic illness (such as diabetes or asthma) did not fill required prescriptions, and only 18 percent of unstably insured adults between the ages of 50 and 64 had been screened for colon cancer in the past 5 years compared with 56 percent of adults insured all year. ${ }^{6}$

Recognizing the important consequences of unstable insurance coverage, the Institute of Medicine, in a 2004 report, identified continuous insurance coverage as one of the five key principles necessary for the success of health care reform. ${ }^{7}$ Motivated by this principle, we used a large, nationally representative sample of US adults to assess comprehensively how individuals with and without continuous insurance coverage differ in terms of receiving preventive care.

\section{Methods}

This study used longitudinal survey data from the Medical Expenditure Panel Survey (MEPS) to examine the impact of gaps in insurance coverage on individuals' utilization of preventive health care services.

\section{Data Source and Study Population}

The MEPS Household Component is a survey of the US civilian, noninstitutionalized population conducted each year since 1996 by the Agency for Healthcare Research and Quality (AHRQ) under the US Department of Health and Human Services. The sampling frame is drawn from respondents to the National Health Interview Survey, which is conducted by the National Center for Health Statistics. MEPS uses an overlapping panel design in which a new panel of sample households is selected each year. Two full years of data for each panel are collected in five rounds of computer-assisted in-person interviews that take place over a 30-month period. Certain populations are oversampled, including Asians, Hispanics, blacks, and families with incomes below 200 percent of the federal poverty threshold (FPT). ${ }^{8}$ A population weight variable provided by AHRQ in the data files allows analysts to calculate nationally representative estimates.

We used data from the longitudinal file for Panel 11, covering calendar years 2006 and 2007. We selected this time period because it was prior to the implementation of health care reform (other than in Massachusetts) and the economic downturn that began in 2008. The Panel 11 file contains a longitudinal weight variable; all variables from the 2006 and 2007 consolidated full-year files; and the strata and sampling unit values from the fullyear consolidated files and the pooled variance data file. The overall response rate for Panel 11 was 55.4 percent. ${ }^{9}$ 


\section{Outcome Variables and Measures}

Sample characteristics included age at baseline, sex, race/ethnicity, educational attainment at baseline, English proficiency, perceived health, urban/rural residence at baseline, census region at baseline, family income category (low income: under 200 percent of the FPT; middle income: 200 to 399 percent of the FPT; and high income: 400 percent of the FPT or greater), and employment status (continuously employed, continuously unemployed/ not working [including homemaker, retired, or student], or intermittently employed). Family income and employment were assessed at five time points covering 2 full years. We assigned people who switched income categories during the study period to the low-income group if they were categorized as low income in either year, to the middle-income group if they were categorized as middle income in one year and high income in the other year, and to the high-income group only if they were in the highincome group in both years.

We categorized respondents as insured or not insured for each month over the 24-month study period; each month of insurance was then further categorized as "private only" or "any public" (public includes Medicare, Medicaid, military, and state or other programs). We classified people with both public and private insurance in the "any public insurance" group for the purposes of this analysis because the characteristics of those who qualify for public insurance (in terms of poverty and/or disability) are different from those who do not.

The primary outcome variable was receipt of appropriate preventive services as assessed at the final interview at the end of the study period for people between the ages of 18 and 64 years at baseline. We restricted the sample to adults between the ages of 18 and 64 years because of the policy relevance of this population under health care reform and the Medicaid expansion. We analyzed receipt of recommended preventive care for the following seven individual measures and overall:

1. a routine checkup within the past 2 years for people 18 years or older

2. a blood pressure check within the past 2 years for people 18 years or older
3. a cholesterol check within the past 5 years for men 35 years or older and women 45 years or older

4. a flu shot in the past year for people 50 years or older

5. a sigmoidoscopy or colonoscopy at any previous time for people between the ages of 50 and 64 years

6. a mammogram in the past 2 years for women between the ages of 50 and 64 years

7. a Pap smear in the past 2 years for women between the ages of 18 and 64 years

All selected measures, except for routine checkups, were A- or B-level recommendations from the US Preventive Services Task Force (USPSTF), and definitions for who should receive each service were taken from the USPSTF website. ${ }^{10}$ We included routine checkups, although not recommended per se, to proxy the receipt of other A- and B-level recommended preventive screening measures that are recommended by the USPSTF but not assessed in MEPS, such as healthy diet counseling and intimate partner violence screening. The ACA requires most health plans to cover A- and B-level recommended preventive services at no cost to the beneficiary.

Ideally, individuals in the 50- to 75-year-old age group would undergo fecal occult blood tests (FOBT) annually, sigmoidoscopies every 5 years, and colonoscopies every 10 years. ${ }^{11}$ However, the MEPS data did not allow us to evaluate the proportion who received this level of care in detail, because it had no questions about FOBT screening.

\section{Data Analysis}

We included in the analysis all respondents between the ages of 18 and 64 years at baseline with data from all five rounds of Panel 11. The statistical analyses were conducted using SAS version 9.2 and incorporated sampling weights, primary sampling units, and strata to account for the complex survey design and to derive nationally representative estimates. Here, we report unweighted Ns and weighted percentages of those within categories of selected covariates. Wald chi-squared statistics were calculated for the descriptive analyses. 
We conducted multivariable analyses using separate logistic regression models for each outcome. The model covariates varied depending on the population at risk; for example, the model for mammogram did not include age or sex as covariates because the model population included only women in the oldest age group. All models included race, limited English proficiency, education, urbanicity, census region, family income category, perceived health, and employment status as covariates.

\section{Results}

The sample of adults between the ages of 18 and 64 years at baseline $(\mathrm{n}=8,985$, representing $178,861,924$ individuals) had a mean age of 41 years. Table 1 provides sociodemographic characteristics of the sample (with weighted percentages). Of the overall sample, 56 percent had continuous private insurance, 10 percent had continuous public coverage, 21 percent had intermittent insurance, and 14 percent

Table 1. Sociodemographic characteristics overall and by insurance subgroup (weighted percentages)

\begin{tabular}{|c|c|c|c|c|c|c|c|c|}
\hline Measure & $\begin{array}{l}\overline{\overline{5}} \\
\text { वे }\end{array}$ & 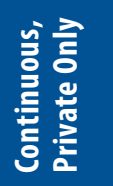 & 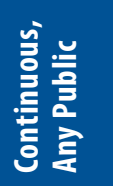 & 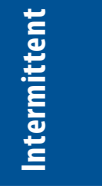 & 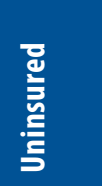 & 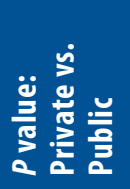 & 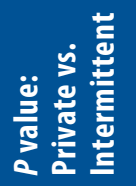 & 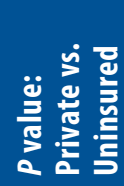 \\
\hline Unweighted N & 8,985 & 4,272 & 1,158 & 1,974 & 1,581 & & & \\
\hline Age (baseline) & & & & & & $<.001$ & $<.001$ & $<.001$ \\
\hline $18-29$ years & $25.9 \%$ & $19.3 \%$ & $18.3 \%$ & $41.0 \%$ & $35.7 \%$ & & & \\
\hline $30-44$ years & $33.5 \%$ & $35.8 \%$ & $23.2 \%$ & $32.4 \%$ & $33.5 \%$ & & & \\
\hline $45-64$ years & $40.6 \%$ & $44.9 \%$ & $58.5 \%$ & $26.6 \%$ & $30.8 \%$ & & & \\
\hline Sex & & & & & & $<.001$ & .492 & $<.001$ \\
\hline Male & $49.1 \%$ & $48.1 \%$ & $41.7 \%$ & $49.1 \%$ & $58.4 \%$ & & & \\
\hline Female & $50.9 \%$ & $51.9 \%$ & $58.3 \%$ & $50.9 \%$ & $41.6 \%$ & & & \\
\hline Race/ethnicity & & & & & & $<.001$ & $<.001$ & $<.001$ \\
\hline White, non-Hispanic & $67.2 \%$ & $75.5 \%$ & $60.5 \%$ & $59.4 \%$ & $49.4 \%$ & & & \\
\hline Black, non-Hispanic & $11.7 \%$ & $9.1 \%$ & $19.2 \%$ & $14.6 \%$ & $12.6 \%$ & & & \\
\hline Multiple races/other & $6.9 \%$ & $6.8 \%$ & $8.2 \%$ & $7.3 \%$ & $5.8 \%$ & & & \\
\hline Hispanic, any race & $14.2 \%$ & $8.6 \%$ & $12.1 \%$ & $18.7 \%$ & $32.2 \%$ & & & \\
\hline Limited English proficiency & & & & & & $<.001$ & $<.001$ & $<.001$ \\
\hline Yes & $5.9 \%$ & $2.2 \%$ & $5.1 \%$ & $7.2 \%$ & $20.3 \%$ & & & \\
\hline No & $94.1 \%$ & $97.8 \%$ & $94.9 \%$ & $92.8 \%$ & $79.7 \%$ & & & \\
\hline Education (baseline) & & & & & & $<.001$ & $<.001$ & $<.001$ \\
\hline Less than 12 years & $14.7 \%$ & $7.0 \%$ & $24.9 \%$ & $18.5 \%$ & $32.9 \%$ & & & \\
\hline $\begin{array}{l}12 \text { years or high school } \\
\text { equivalent }\end{array}$ & $30.7 \%$ & $26.6 \%$ & $36.6 \%$ & $34.8 \%$ & $37.3 \%$ & & & \\
\hline Any college & $54.6 \%$ & $66.4 \%$ & $38.5 \%$ & $46.8 \%$ & $29.8 \%$ & & & \\
\hline Urbanicity (baseline) & & & & & & .012 & .372 & .061 \\
\hline Urban & $84.1 \%$ & $84.8 \%$ & $79.5 \%$ & $86.0 \%$ & $81.5 \%$ & & & \\
\hline Rural & $15.9 \%$ & $15.2 \%$ & $20.5 \%$ & $14.0 \%$ & $18.5 \%$ & & & \\
\hline Region (baseline) & & & & & & .269 & $<.001$ & $<.001$ \\
\hline Northeast & $18.5 \%$ & $20.0 \%$ & $21.6 \%$ & $16.6 \%$ & $12.9 \%$ & & & \\
\hline Midwest & $22.0 \%$ & $24.8 \%$ & $21.1 \%$ & $18.7 \%$ & $15.6 \%$ & & & \\
\hline South & $36.1 \%$ & $33.7 \%$ & $34.8 \%$ & $37.1 \%$ & $45.6 \%$ & & & \\
\hline West & $23.4 \%$ & $21.5 \%$ & $22.5 \%$ & $27.6 \%$ & $25.8 \%$ & & & \\
\hline
\end{tabular}




\begin{tabular}{|c|c|c|c|c|c|c|c|c|}
\hline Measure & 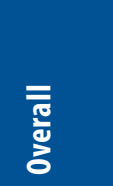 & 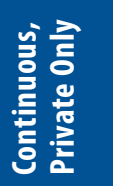 & 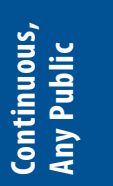 & 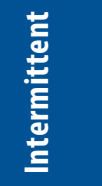 & 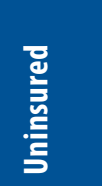 & 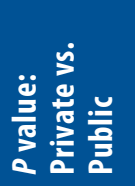 & 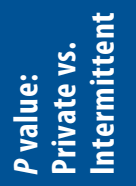 & 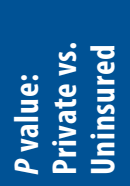 \\
\hline Perceived health (baseline) & & & & & & $<.001$ & $<.001$ & $<.001$ \\
\hline Excellent/very good & $64.7 \%$ & $78.6 \%$ & $41.9 \%$ & $59.6 \%$ & $60.1 \%$ & & & \\
\hline Good & $26.1 \%$ & $17.1 \%$ & $40.1 \%$ & $30.2 \%$ & $28.8 \%$ & & & \\
\hline Fair/poor & $9.2 \%$ & $4.3 \%$ & $18.0 \%$ & $10.2 \%$ & $11.1 \%$ & & & \\
\hline Income categorya & & & & & & $<.001$ & $<.001$ & $<.001$ \\
\hline Low income & $33.8 \%$ & $14.4 \%$ & $59.5 \%$ & $52.0 \%$ & $66.6 \%$ & & & \\
\hline Middle income & $31.5 \%$ & $35.4 \%$ & $19.5 \%$ & $30.1 \%$ & $26.9 \%$ & & & \\
\hline High income & $34.7 \%$ & $50.2 \%$ & $21.0 \%$ & $17.8 \%$ & $6.5 \%$ & & & \\
\hline Employment category & & & & & & $<.001$ & $<.001$ & $<.001$ \\
\hline Continuously employed & $69.9 \%$ & $83.2 \%$ & $28.2 \%$ & $60.6 \%$ & $60.3 \%$ & & & \\
\hline Continuously unemployed & $10.9 \%$ & $5.9 \%$ & $39.8 \%$ & $8.7 \%$ & $13.1 \%$ & & & \\
\hline $\begin{array}{l}\text { Switched employment } \\
\text { categories }\end{array}$ & $19.3 \%$ & $10.9 \%$ & $32.0 \%$ & $30.8 \%$ & $26.6 \%$ & & & \\
\hline
\end{tabular}

a Low income designates those who were categorized as low income in either year. Middle income designates those who were categorized as middle income or high income in either year. High income designates those who were categorized as high income in both years.

Source: Authors' calculations based on Medical Expenditure Panel Survey 2006-2007 data.

were continuously uninsured (calculated using sampling weights to derive nationally representative percentages).

The sample consisted of 34 percent in the low-income category (19 percent with low incomes in both years), 32 percent in the middle-income category (18 percent in both years), and 35 percent with high incomes in both years. About 70 percent of the sample was continuously employed for both years, while 19 percent had intermittent employment during the 2-year period and 11 percent were unemployed, on leave, retired, or homemakers for both years.

On most measures, individual characteristics between the insurance groups differed significantly. For example, a larger proportion of the uninsured were Hispanic (32 percent), had limited English proficiency (20 percent), and were low income (67 percent). In contrast, the continuous privately insured group was largely white, non-Hispanic (76 percent) with some college education (66 percent) and high income (50 percent).

\section{Receipt of Preventive Care}

About 91 percent of the overall sample received at least one of the seven individual preventive care services, but only 40 percent received all recommended preventive services for their age and sex group (ranging from 25 percent of those in the uninsured group to 46 percent of those in the continuous private insurance group; see Table 2, next page). The proportion receiving none of the recommended care was around 5 percent in the continuous private insurance group, 4 percent in the public insurance group, more than 11 percent in the intermittent-coverage group, and 29 percent in the uninsured group.

Overall, nearly 30 percent of adults had not received a routine checkup in the past 2 years, and about 13 percent had not received a blood pressure check within the past 2 years (Table 2). Half of the eligible respondents had not had their cholesterol checked within the past 5 years. More than half had not received a flu shot in the past year. About one-quarter of the eligible respondents had not been screened for breast cancer or cervical cancer in the past 2 years. Half had never been screened for colon cancer. 
Table 2. Receipt of recommended preventive care by insurance status among adults between the ages of 18 and 64 at baseline (unweighted Ns and weighted percentages)

\begin{tabular}{|c|c|c|c|c|c|}
\hline Measure and relevant population & Overall & $\begin{array}{l}\text { Continuous, } \\
\text { Private Only }\end{array}$ & $\begin{array}{l}\text { Continuous, } \\
\text { Any Public }\end{array}$ & Intermittent & Uninsured \\
\hline \multicolumn{6}{|l|}{ Received all recommended preventive care services } \\
\hline Unweighted N (adults 18-64 years) & 8,985 & 4,272 & 1,158 & 1,974 & 1,581 \\
\hline Weighted percent & $39.5 \%$ & $46.3 \%$ & $28.5 \%$ & $44.2 \%$ & $25.2 \%$ \\
\hline \multicolumn{6}{|l|}{ Received no recommended preventive care services } \\
\hline Unweighted N (adults 18-64 years) & 8,985 & 4,272 & 1,158 & 1,974 & 1,581 \\
\hline Weighted percent & $9.5 \%$ & $5.1 \%$ & $4.0 \%$ & $11.3 \%$ & $29.4 \%$ \\
\hline \multicolumn{6}{|l|}{ Routine checkup, past 2 years } \\
\hline Unweighted N (adults 18-64 years) & 8,985 & 4,272 & 1,158 & 1,974 & 1,581 \\
\hline Weighted percent & $71.6 \%$ & $78.4 \%$ & $82.7 \%$ & $64.3 \%$ & $46.4 \%$ \\
\hline \multicolumn{6}{|l|}{ Blood pressure checked, past 2 years } \\
\hline Unweighted N (adults 18-64 years) & 8,985 & 4,272 & 1,158 & 1,974 & 1,581 \\
\hline Weighted percent & $87.0 \%$ & $92.0 \%$ & $93.9 \%$ & $84.5 \%$ & $64.8 \%$ \\
\hline \multicolumn{6}{|l|}{ Cholesterol checked, past 5 years } \\
\hline $\begin{array}{l}\text { Unweighted N (men 35-64 years, women 45-64 } \\
\text { years) }\end{array}$ & 4,108 & 2,003 & 434 & 849 & 822 \\
\hline Weighted percent & $50.3 \%$ & $59.1 \%$ & $72.1 \%$ & $37.0 \%$ & $25.3 \%$ \\
\hline \multicolumn{6}{|l|}{ Flu shot, past year } \\
\hline Unweighted N (adults 50-64 years) & 2,587 & 1,364 & 529 & 352 & 342 \\
\hline Weighted percent & $44.1 \%$ & $46.4 \%$ & $57.6 \%$ & $34.5 \%$ & $18.7 \%$ \\
\hline \multicolumn{6}{|l|}{ Mammogram, past 2 years } \\
\hline Unweighted N (women 50-64 years) & 1,384 & 720 & 292 & 179 & 193 \\
\hline Weighted percent & $76.6 \%$ & $84.0 \%$ & $79.1 \%$ & $60.5 \%$ & $46.0 \%$ \\
\hline \multicolumn{6}{|l|}{ Pap smear, past 2 years } \\
\hline Unweighted N (women 18-64 years) & 4,877 & 2,269 & 724 & 1,125 & 759 \\
\hline Weighted percent & $76.7 \%$ & $83.4 \%$ & $72.6 \%$ & $73.2 \%$ & $53.0 \%$ \\
\hline \multicolumn{6}{|l|}{ Colon cancer screening, ever } \\
\hline Unweighted N (adults 50-64 years) & 2,587 & 1,364 & 529 & 352 & 342 \\
\hline Weighted percent & $50.2 \%$ & $54.5 \%$ & $57.9 \%$ & $43.0 \%$ & $20.5 \%$ \\
\hline
\end{tabular}

Note: Frequencies are the weighted proportions of those recommended to receive each service by the US Preventive Services Task Force ${ }^{10}$ (grade A/B recommendations), limited to those 18 to 64 years old at baseline, ascertained at the end of the study period.

Source: Authors' calculations based on Medical Expenditure Panel Survey 2006-2007 data. 
In multivariable regression analyses, those with continuous insurance had essentially the same odds of receiving no preventive services, whether the coverage was public or private (Table 3 ). In contrast, having intermittent coverage increased the odds of receiving no preventive services to 1.64 compared with continuous private insurance. Continuously lacking insurance increased the odds of receiving no preventive services to 4.41 , compared with continuous private coverage. Other significant positive predictors of receiving no preventive services included younger age, male sex, limited English proficiency, lower educational attainment, residing in the West (vs. Northeast), excellent or very good perceived health (vs. fair/poor), and low income.

Having continuous public insurance (e.g., Medicaid) was associated with a significant decrease in the likelihood of not receiving a flu shot or cholesterol check (Figure 1, next page). On other measures, the continuous public insurance group's risk did not differ significantly from that of the continuous private insurance group's risk.

Compared with the private-coverage group, the intermittent-coverage group had a significantly increased risk of not receiving the specified preventive care services on almost every individual measure (Figure 1). Only the colonoscopy measure showed no significant effect of intermittent coverage compared with private coverage (odds ratio [OR] 1.32 with a $95 \%$ confidence interval [CI] of 0.963 to 1.808 ). ORs ( $95 \%$ CIs) on the other six measures were as follows: no checkup, 1.57 (1.32 to 1.86); no blood pressure check, 1.63 (1.30 to 2.04); no flu shot, 1.64 (1.20 to 2.24); no cholesterol check, 2.04 (1.67 to 2.49); no mammogram, 2.68 (1.69 to 4.24); and no Pap smear, 1.79 (1.45 to 2.21).

Finally, the uninsured group was at significantly increased risk of not receiving individual preventive services compared with the continuous private group; ORs (95\% CIs) ranged from a low of 2.85 (2.36 to 3.44) for not receiving a routine checkup to 4.69 (2.98 to 7.39 ) for not receiving a mammogram.
Table 3. Effects of insurance coverage and other characteristics on the odds of receiving no preventive services

\begin{tabular}{|c|c|c|}
\hline Covariate & $\begin{array}{l}\text { Odds } \\
\text { Ratio }\end{array}$ & $\begin{array}{c}95 \% \\
\text { Confidence } \\
\text { Interval }\end{array}$ \\
\hline \multicolumn{3}{|c|}{ Insurance category, vs. continuous private } \\
\hline Continuous public & 0.86 & $0.55-1.34$ \\
\hline Intermittent & 1.64 & $1.28-2.09$ \\
\hline Uninsured & 4.41 & $3.27-5.93$ \\
\hline \multicolumn{3}{|l|}{ Age (baseline), vs. $45-64$ years } \\
\hline $18-29$ years & 2.19 & $1.67-2.88$ \\
\hline $30-44$ years & 1.72 & $1.34-2.20$ \\
\hline \multicolumn{3}{|l|}{ Sex } \\
\hline Male, vs. female & 3.00 & $2.49-3.63$ \\
\hline \multicolumn{3}{|l|}{ Race/ethnicity } \\
\hline White, non-Hispanic, vs. all others & 1.14 & $0.91-1.42$ \\
\hline \multicolumn{3}{|l|}{ English proficiency } \\
\hline $\begin{array}{l}\text { Limited English proficiency, vs. } \\
\text { proficient in English }\end{array}$ & 2.26 & $1.58-3.23$ \\
\hline
\end{tabular}

\begin{tabular}{lll}
\hline Education (baseline), vs. any college & & \\
\hline Less than 12 years & $\mathbf{1 . 3 9}$ & $\mathbf{1 . 0 8 - 1 . 7 9}$ \\
\hline $\begin{array}{l}12 \text { years or high school } \\
\text { equivalency }\end{array}$ & $\mathbf{1 . 5 0}$ & $\mathbf{1 . 1 9 - 1 . 9 0}$ \\
\hline
\end{tabular}

\begin{tabular}{|c|c|c|}
\hline \multicolumn{3}{|l|}{ Urbanicity (baseline) } \\
\hline Rural, vs. urban & 1.01 & $0.75-1.35$ \\
\hline \multicolumn{3}{|l|}{ Census region (baseline), vs. Northeast } \\
\hline Midwest & 1.27 & $0.89-1.79$ \\
\hline South & 1.12 & $0.80-1.56$ \\
\hline West & 1.52 & $1.10-2.11$ \\
\hline \multicolumn{3}{|l|}{ Perceived health (baseline), vs. fair/poor } \\
\hline Excellent/very good & 1.57 & $1.15-2.13$ \\
\hline Good & 1.19 & $0.83-1.71$ \\
\hline \multicolumn{3}{|l|}{ Income, ${ }^{\text {a }}$ vs. high } \\
\hline Low & 1.71 & $1.22-2.40$ \\
\hline Middle & 1.25 & $0.90-1.74$ \\
\hline \multicolumn{3}{|c|}{ Employment, vs. continuously unemployed } \\
\hline Continuously employed & 1.33 & $0.93-1.88$ \\
\hline Switched employment categories & 1.23 & $0.84-1.78$ \\
\hline
\end{tabular}

a Low income designates those who were categorized as low income at any point during the study period. Middle income designates those who were categorized as middle income or high income at any point during the study period. High income designates those who were categorized as high income in both years. Model adjusted for age, sex, race/ethnicity, limited English proficiency, education, urbanicity, region, perceived health, income, and employment status.

Note: Bold indicates a significant predictor for receiving no preventive services. Source: Authors' calculations based on Medical Expenditure Panel Survey 2006-2007 data. 


\section{Figure 1. Effects of insurance status on adjusted odds of not receiving seven individual recommended preventive services, compared with people with continuous private insurance}

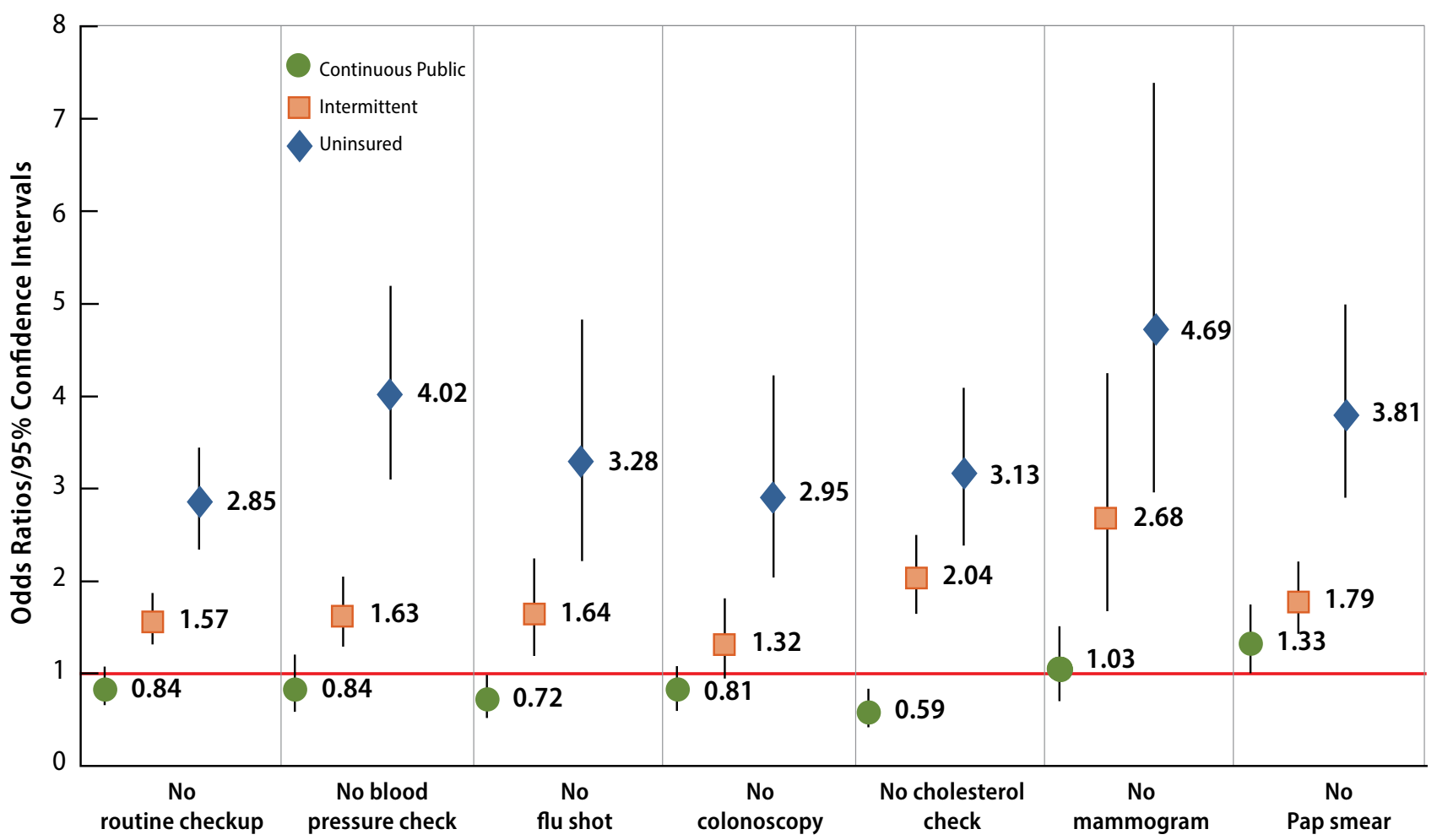

Legend: This figure shows odds ratios and 95\% confidence intervals for seven individual preventive services, which were calculated using seven separate logistic regression models. The reference group for each model was the "continuous insurance, private only" group. Covariates included age and sex (where appropriate), race, limited English proficiency, education, urbanicity, census region, family income, perceived health, and employment status.

Source: Authors' calculations based on Medical Expenditure Panel Survey 2006-2007 data.

\section{Discussion}

In this study, we found that having any gap in insurance coverage and being uninsured are significant risk factors for not receiving preventive care. Having intermittent coverage increased the risk of receiving no preventive services more than did race/ethnicity, education, where individuals lived, perceived health status, or employment status. The effect of intermittent coverage was less than the effects of age, sex, English proficiency, and income. However, lack of continuous insurance coverage is a modifiable risk factor, unlike many of the other predictors that cannot be changed easily.

We also found in the adjusted analyses that those in the "continuous, any public" insurance group were at significantly lower risk of not receiving a flu shot or cholesterol check. Unadjusted rates of receiving preventive services were higher in this group as well, except for mammograms and Pap smears. Perhaps because people in the "any public insurance" group had worse health status than the private-only group, they were more likely to have multiple contacts with the health care system, leading to more opportunities for providers to screen them for various conditions. Although our methods differed, a recent study using 2007-2008 MEPS data found higher rates of blood pressure screening and cholesterol screening in a publicly insured group compared with a group with private-only coverage. ${ }^{12}$

Our study differs from previous studies in that we included the subset of patients who are neither uninsured nor insured but have inconsistent insurance status. This population is often excluded from analyses on the effect of being uninsured. ${ }^{12} \mathrm{We}$ focused on adults between the ages of 18 and 64 years at baseline, which is the population most affected by the ACA and Medicaid expansions. To answer our research questions, we clearly defined a broad set of relevant preventive services that are applicable 
to this population and used a nationwide, highquality survey data set that included nearly 9,000 respondents.

Because this study used retrospective survey data (MEPS), it was subject to the limitations of MEPS, of the survey data, and of retrospective studies in general, including underreporting of the receipt of preventive services. Specifically, insurance status and receipt of preventive care services are based on selfreport; no attempt is made to verify these responses. Although the study included a representative sample of noninstitutionalized US adults, the results may not be generalizable to other populations. Moreover, the data are from 2006 to 2007 and may not reflect current trends.

Lack of health insurance has been previously linked with a wide range of serious consequences, including receiving fewer preventive and diagnostic services, being more severely ill when diagnosed, and receiving less therapeutic care. ${ }^{13}$ Among individuals with cancer, those with inadequate insurance coverage are more likely to be diagnosed at a later stage ${ }^{14}$ and have poorer survival. ${ }^{5}$ As we found in this study, being uninsured and having gaps in insurance are both risk factors for not receiving preventive cancer screenings.

In addition, having continuous health insurance is associated with a lower probability of going to the emergency department, ${ }^{15}$ greater use of physician services and preventive services, higher selfreported health status, and lower mortality. ${ }^{16}$ By improving access to care, health insurance coverage is fundamentally important to better health care and health outcomes. ${ }^{17}$

The ACA requires that insurance plans issued on or after September 23, 2010 (or August 1, 2012, for certain services) cover a wide range of preventive services at no cost to the enrollee: 15 covered services for all adults, an additional 22 for women, and an additional 26 for children. ${ }^{18} \mathrm{~A}$ study of the likely cost-effectiveness of a package of 20 preventive services (including all of the services measured in this study) found that, if uptake reached 90 percent, it could avert the loss of more than 2 million life-years and save $\$ 3.7$ billion annually. ${ }^{19}$

The ACA will not solve all the problems with access to care for previously uninsured individuals. Even with the ACA, the United States will continue to have a substantial number of uninsured people, and although the ACA includes provisions to increase access to preventive care, these provisions do not apply to the uninsured. In Massachusetts, where legislation similar to the ACA has been in effect since 2006, evidence suggests some individuals have difficulty maintaining insurance coverage with Massachusetts's exchange, known as Commonwealth Care, because of recertification requirements and communication problems. ${ }^{20}$

The United States may not have more intermittently covered people after the ACA is fully implemented than before the Act-in fact, we may have fewer. The point is that intermittent insurance is a modifiable risk factor for undesirable outcomes, and just enrolling people will not be enough-maintaining coverage will also be important. Although access to new benefits, such as no-cost preventive services, has the potential to yield enormous gains in addressing disparities and reducing chronic illness, maintaining continuous insurance will be critical to facilitating this access. Thus, the ACA may partially, but not completely, solve the problems associated with access to care for previously uninsured individuals.

\section{References}

1. Collins SR, Robertson R, Garber T, Doty MM. Gaps in health insurance: why so many Americans experience breaks in coverage and how the Affordable Care Act will help. New York: Commonwealth Fund; 2012 [cited 2013 Jul 5]. Available from: http://www.commonwealthfund. org/Publications/Issue-Briefs/2012/Apr/Gaps-inHealth-Insurance.aspx
2. Internal Revenue Service: Questions and answers on the individual shared responsibility provision. Washington: Internal Revenue Service; 2013 [cited 2014 Mar 17]. Available from: http://www. irs.gov/uac/Questions-and-Answers-on-theIndividual-Shared-Responsibility-Provision 
3. Henry J. Kaiser Family Foundation. Status of state action on the Medicaid expansion decision, 2014. Menlo Park (CA): The Foundation; [cited 2014 Feb 15]. Available from: http://kff.org/healthreform/state-indicator/state-activity-aroundexpanding-medicaid-under-the-affordable-careact/

4. Bradford WD, Kaste LM, Nietert PJ. Continuity of medical care, health insurance, and nonmedical advice in the first 3 years of life. Med Care. 2004 Jan;42(1):91-8. PubMed PMID: 14713743.

5. Ward E, Halpern M, Schrag N, Cokkinides V, DeSantis C, Bandi P, Siegel R, Stewart A, Jemal A. Association of insurance with cancer care utilization and outcomes. CA Cancer J Clin. 2008 Jan-Feb;58(1):9-31. PubMed PMID: 18096863.

6. Collins SR, Davis K, Doty MM, Kriss JL, Holmgren AL. Gaps in health insurance: an allAmerican problem. New York: Commonwealth Fund; 2006 [cited 2013 Jul 5]. Available from: http://www.commonwealthfund.org/usr_doc /Collins_gapshltins_920.pdf

7. Institute of Medicine, Committee on the Consequences of Uninsurance. Insuring America's health: principles and recommendations. Washington: National Academies Press; 2004 [cited 2014 Feb 17]. Available from: http://www. iom.edu/reports/2004/insuring-americas-healthprinciples-and-recommendations.aspx

8. Agency for Healthcare Research and Quality. MEPS survey background. Rockville (MD): Department of Health and Human Services (US), Agency for Healthcare Research and Quality; 2009 [cited 2010 Dec 14]. Available from: http://meps. ahrq.gov/mepsweb/about_meps/survey_back.jsp

9. Agency for Healthcare Research and Quality. MEPS HC-113: 2007 full year consolidated data file. Rockville (MD): Department of Health and Human Services (US), Agency for Healthcare Research and Quality; 2009 [cited 2010 Dec 14]. Available from: http://meps.ahrq.gov/mepsweb/ data_stats/download_data/pufs/h113 /h113doc.shtml
10. US Preventive Services Task Force. USPSTF A and $B$ recommendations. Rockville (MD): Preventive Services Task Force (US); [updated 2014 Jan; cited 2013 Feb 13]. Available from: http:// www.uspreventiveservicestaskforce.org/uspstf /uspsabrecs.htm

11. Centers for Disease Control and Prevention. Colorectal cancer screening guidelines. Atlanta: Centers for Disease Control and Prevention; 2013; [updated 2014 Feb 26] [cited 2013 Sep 19]. Available from: http://www.cdc.gov/cancer /colorectal/basic_info/screening/guidelines.htm

12. Abdus S, Selden TM. Preventive services for adults: how have differences across subgroups changed over the past decade? Medical care. 2013;51(11):999-1007. PubMed Central PMCID: 24036996.

13. Hadley J. Sicker and poorer-the consequences of being uninsured: a review of the research on the relationship between health insurance, medical care use, health, work, and income. Med Care Res Rev. 2003 Jun;60(2 Suppl):3S-75S; discussion 6S-112S. PubMed PMID: 12800687.

14. Halpern MT, Ward EM, Pavluck AL, Schrag NM, Bian J, Chen AY. Association of insurance status and ethnicity with cancer stage at diagnosis for 12 cancer sites: a retrospective analysis. Lancet Oncol. 2008 Mar;9(3):222-31. PubMed PMID: 18282806.

15. Gill JM, Mainous AG, 3rd, Nsereko M. The effect of continuity of care on emergency department use. Arch Fam Med. 2000 Apr;9(4):333-8. PubMed PMID: 10776361.

16. Freeman JD, Kadiyala S, Bell JF, Martin DP. The causal effect of health insurance on utilization and outcomes in adults: a systematic review of US studies. Med Care. 2008 Oct;46(10):1023-32. PubMed PMID: 18815523.

17. Hoffman C, Paradise J. Health insurance and access to health care in the United States. Ann NY Acad Sci. 2008;1136:149-60. PubMed PMID: 17954671. 
18. Department of Health and Human Services. Preventive services covered under the Affordable Care Act. Washington: Department of Health and Human Services (US); 2010 Sep 23 [updated 2012 Sep 27; cited 2014 Feb 14]. Available from: http:// www.hhs.gov/healthcare/facts/factsheets/2010/07/ preventive-services-list.html

19. Maciosek MV, Coffield AB, Flottemesch TJ, Edwards NM, Solberg LI. Greater use of preventive services in US health care could save lives at little or no cost. Health Aff (Millwood). 2010 Sep;29(9):1656-60. PubMed PMID: 20820022.
20. Dennis A, Clark J, Córdova D, McIntosh J, Edlund K, Wahlin B, Tsikitas L, Blanchard K. Access to contraception after health care reform in Massachusetts: a mixed-methods study investigating benefits and barriers. Contraception. 2012;85(2):166-72. PubMed Central PMCID: 22067781. 



\section{Acknowledgments}

This research was supported by an RTI International internal research and development grant. The authors gratefully acknowledge Sharon Barrell for editorial assistance in preparing the manuscript. 
RTI International is an independent, nonprofit research organization dedicated to improving the human condition by turning knowledge into practice. RTI offers innovative research and technical solutions to governments and businesses worldwide in the areas of health and pharmaceuticals, education and training, surveys and statistics, advanced technology, international development, economic and social policy, energy and the environment, and laboratory and chemistry services.

The RTI Press complements traditional publication outlets by providing another way for RTI researchers to disseminate the knowledge they generate. This PDF document is offered as a public service of RTI International. 